\title{
VINCENT WALLACE, REPRESENTANTE DEL ROMANTICISMO EN LA ÓPERA INGLESA
}

\author{
JORGE VELAZCO
}

\section{A Manuel Covarrubias}

William Wallace nació el 11 de marzo de 1812 en Waterford, ciudad donde radicaba el $29^{\circ}$ regimiento de infantería "Worcestershire", en el cual prestaba sus servicios su padre, el sargento William Wallace, director de la banda del tegimiento. En 1825, el sargento Wallace fue licenciado del ejército y la familia se fue a vivir a Dublín. Bajo la dirección de su padre, el pequeño William aprendió a tocar diversos instrumentos y a poco de su llegada a Irlanda trabajaba como violín segundo en la orquesta del Teatro Real. Al parecer, su talento musical era de muy clara esencia, ya que pronto pudo tocar con fluidez tanto el piano como el órgano, y alguna vez llegó a sustituir al concertino del conjunto.

En enero de 1830, Wallace fue designado organista titular de la catedral de Thurles y profesor de música en el convento de las ursulinas de la ciudad. Ese nombramiento resultó capital en su vida, ya que se enamoró de una de sus alumnas, Isabella Kelly, lo que le llevó a convertirse al catolicismo, pues el padre de su novia se oponía a sus relaciones a causa de su vinculación con el credo protestante, en el que había nacido. Wallace fue bautizado en el otoño de 1830 , adoptando el nombre de Vincent, que usó por el resto de su vida como nombre principal, y se casó con Isabella al año siguiente. En ągosto de 1831 regresó a Dublín con su esposa y reingresó en la orquesta del Teatro Real. Allí recibió un tremendo estímulo a causa de las visitas de Paganini (1832-1840), al grado de que en 1834 se presentó como compositor y virtuoso del violín, tocando un concierto propio, en una velada de la Sociedad Anacreóntica de Dublín.

Al año siguiente, decidió emigrar a Tasmania y viajó desde Liverpool hasta Hobart en un largo recorrido marino que duró el 9 de julio al 31 de octubre. Lo acompañaban su esposa y su cuñada, Anná Kelly. En Hobart presentó un breve número de recitales y en enero de 1836 viajó a Sydney, donde decidió establecerse como virtuoso del piano y del violín. Su debut como concertista doble tuvo lugar en el Hotel Royal, bajo el patrocinio de Sir Richard Bourke, gobernador de Nueva Gales del Sur. Tocó un concierto para piano de Herz (1803-1888) y un concierto para violín de Mayseder (1789-1863), el amigo de Beethoven. 
Durante toda la mitad de su carrera musical, que dedicó al concertismo, se presentó siempre con esa calidad dual de violinista y pianista. Al parecer, era un pianista competente, pero la mayor impresión que causó fue como violinista y pronto los periódicos australianos, maravillados por su virtuosismo, le llamaban "el Paganini australiano" y se le consideró como "el primer gran concertista que visitó Australia".

El 4 de abril de 1836, Wallace, su hermana Eiza (1814-1879) -que vivía en Sydney casada con el cantante australiano John Bushelle-- y su esposa, inauguraron una escuela de música en Bridge Street, bajo el patrocinio del gobernador, que tenía como finalidad la instrucción musical de las jóvenes de buena sociedad. Se dice que también se dedicó a la ganadería lanar, pero no hay documentación de este rumor, que aparece como justificante de su huída de Australia, el 11 de febrero de 1838. Wallace abandonó al país, a su esposa y a su pequeño hijo William y dejó detrás deudas por más de dos mil libras esterlinas, sin que haya clara explicación de la razón de su decisión de abandonar a su familia.

Wallace dijo posteriormente que se había incorporado a una expedición punitiva contra las maoríes en Nueva Zelandia y que después había llegado a la India, donde supuestamente prestó impottantes servicios a la Begum de Oudj. Estos rumores fueron recogidos por Berlioz (1803-1869), pero actualmente parece que la única deslumbrante aventura que puede documentarse de esa época es un viaje a Chile, donde se estableció en Valparaíso, como miembro de la comunidad británica en la ciudad, donde fue parte de un grupo "activo y progresista ... muy influyente en el desarrollo de la música chilena", según el musicólogo Eugenio Pereira Salas ' (1904). El 3 de junio de 1838, tocó en Valaparaíso su acostumbrado recital como pianista y violinista, y después se presentó en Santiago de Chile con el mismo carácter de virtuoso doble.

En los años siguientes viajó a Buenos Aires, Lima, Jamaica y Cuba, para llegar hasta la ciudad de México, donde dirigió una de las temporadas de las compañías italianas itinerantes en 1841 y compuso una misa con el fin de que se cantara en la catedral.

El 4 de noviembre de 1840 , tuvo lugar un concierto con grandes formalidades, en el Teatro Principal, que fue "la última nota de arte de ese año y la más brillante", en el que se presentó "el célebre violinista, pianista y compositor Guillermo Vicente Wallace, profesor del Real Conservatorio de Londres, director de la Sociedad Anacreóntica de Dublín y gran concertista en los principales teatros europeos". En ese concierto, Wallace tocó las "Variaciones brillantes para violín, de Mayseder", y las "Grandes variaciones para piano, sobre la marcha de Otelo, de Hertz", 
así como la "Gran Fantasía de Paganini, ejecutada sobre una sola cuerda, quitando todas las otras a su violín". El énfasis en sus actuaciones al violín se manifestó en que "A petición de varios aficionados a la música, el Sr. Wallace ejecutará por última vez las aplaudidas variaciones de Paganini, para violín con acompañamiento de orquesta, sobre el tema Nel cor piu non mi sento." El 15 de mayo de 1841, hubo una función a beneficio del actor español Bernardo Avecilla en el Teatro Principal, la cual terminó con las "grandes variaciones de Paganini" ejecutadas por "el distinguido artista Guillermo Vicente Wallace".

De aquí pasó a Nueva Orleáns, donde estuvo en el mismo año, para continuar a Filadelfia (1842) y Boston (1843). Su viaje culminó en Nueva York, donde realizó su doble debut en el Salón Apalo, el 6 de junio de 1843, el cual fue saludado con gran entusiasmo, ya que la prensa lo aclamó como "decididamente el primer violinista y el primer pianista en este paise". Su pièce de résistance era una obrilla consistente de introducción, tema y yariaciones titulada Cracovienne, que tocaba indistintamente en el violín o en el piano. Es posible que Wallace haya salido de Nueva York en 1844, ya que hizo una gira de conciertos por Holanda y Alemania de la que regresó a Inglaterra, donde se presentó en los Hannover Square Rooms el 8 de mayo de 1845, taçando la Cracovienne, en esta ocasión únicamente al piano.

La doble carrera instrumental de Wallace se reflejó en una doble carrera musical de otro género. En 1845 principió a componer con asiduidad y dejó las actividades de intérprete para concentrarse en una nueva carrera como compositor. Entre 1845 y 1865 escribió una serie de piezas para piano, de las que algunas fueron verdaderos best-sellers en Inglaterra: La góndola (1851) y La belle danseuse (1864), aparte de una llovizna de estudios de concierto, variaciones, danzas y piezas características. Algunos díos para piano y obras para violín y piano parecen pertenecer a su época de virtuoso vagabundo.

Los largos años de viajes y aventuras condicionaron una serie de leyenđas románticas acerca de su persona, que fueron determinantes para motivar la curiosidad pública' y formar un ambiente que fue muy favorable a su éxito. El libretista Edward Fitzball, quien había quedado muy impresionado con la capacidad virtuosística de Wallace y andaba bus* cando nuevos talentos artísticos que presentar en Londres, le propuso colaborar para la producción de una ópera, y así apareció la primera de las seis obras escénicas de Wallace. Maritana fue representada por primera vez en el teatro de Drury Lane, el 15 de noviembre de 1845, dirigida por Alfred Bunn (c.1807-1860), y con Emma Romer (c.1814-1868) en el 
papel de Maritana y William Harrison (1813-1868) como Don César. La ópera tuvo un éxito sensacional, que sólo había sido alcanzado en Inglaterra por La gitana (1843) de Balfe (1808-1870), el único autor británico de ópera que alcanzó verdadera fama internacional en el siglo XIX antes de Wallace. Maritana se representó durante cincuenta funciones y el Illustrated London News profetizó el destino de una de sus arias (Scenes that are brightest), que se cumplió a la letra: "será escuchada en todas partes, en el salón dorado y bajo el toldo azul del cielo tocada por el organillo". Algo cursi, pero muy exacto en cuanto a la difusión y popularidad que alcanzó la canción. Maritana fue la llave mágica del triunfo para Wallace y se representó - siempre con éxito muy resonante- en Dublín (1845), Viena (1848), Filadelfia (1848) y en prácticamente todos los grandes centros operáticos del mundo antes de 1850 .

Es muy posible que Wallace haya utilizado mucha música compuesta durante sus correrías en el hemisferio austral para la elaboración de $\mathrm{Ma}$ ritana. Se dijo que la mayor parte había sido escrita en Hobart, en 1835, si bien esta historia podría haber sido inducida por los mismos agentes del autor, ansiosos de rodear a la ópera de un exótico misterio. Incluso se rumoró que otra de sus arias famosas The harp in the air, databa de sus días de maestro y organista en Thurles. Henry Chorley (1808-1872) dijo que Wallace estaba "en busca de un estilo, pues hay media docena de diferentes escuelas que se intentan en otras tantas porciones de la ópera". En relación con los compositores británicos anteriores a Wallace, con excepción de Balfe, Maritana tiene un vigor y una espontaneidad que la colocan en un renglón muy apartado del usual en los autores británicos del siglo XIX, hombres como Edward Loder (1813-1865), John Barnett (1802-1890) o Sir George Macfarren (1813-1887). Algunos de los procedimientos estéticos de Wallace en Maritana pueden detectarse con cierta facilidad y es indudable que contribuyeron a su éxito. Por una parte, el estilo de los temas heroicos, de amplias líneas, característicos de Meyerbeer (1791-1864), aparece en su escena coral tumultuaria con el texto Angels that around us hover, que tiene un impacto inalcanzable para la ballad británica de la época, suave reminiscencia de la Inglaterra rural, tranquila y reposada. El final del acto segundo tiene una buena dosis de la línea continua y sostenida de alto dramatismo, $\tan$ típica de Mozart (1756-1791) e inmediatamente perceptible y disfrutable por el público de la época. Melodias alla italiana (Turn on old time), compatibles con el espíritu de Donizetti (1797-1848) e incluso cercanas al efecto rítmico de la primera época de Verdi (1813-1901) son también elementos claves de Maritana. Actualmente, la ópera puede parecer una mezcla muy abigarra- 
da y de carácter no muy original, pero la luz de un siglo de creación e investigación arroja claridades muy poderosas, que eliminan las sombras que envolvieron a sus contemporáneos. Ello no anula el acierto de Wallace, que fue capaz de crear un sistema musical de comunicación distinto, novedoso y aceptable para su época. El punto más original y valioso de Maritana ha sido señalado brillantemente por el musicólogo británico Nicholas Temperley (1932), quien puso en relieve la capacidad de Watlace para realizar ilustraciones musicales de un color exótico para los ingleses, que podía evocar con gran fuerza los arquetipos españoles y gitanos. It was a knight of princely mien aparece como una premonición de Carmen (1875) de Bizet (1838-1875), con un ritmo de bolero que puede simbolizar fácilmente lo español para el público general de la Gran Bretaña. Hay una canción para decir la fortuna, con un coro, que avanza todavía más la presencia y atmósfera de Carmen (Pretty Gitana, tell us). Esta clase de ideas musicales eran desconocidas en las óperas contemporáneas de ambiente español: La favorita (1840), Don Pasquale (1843) o Ernani (1844), cuyos ritmos de fandango y de bolero fueron expuestos en marcos armónicos de carácter convencional y no con las entonces exóticas armonías de Wallace, tal vez producto de su contacto con la música popular en su experiencia viajera por Iberoamérica, que superaron aún al extraordinario y original genio armónico de Chopin (1810-1849), quien compuso un Bolero (1834) muy avanzado, pero no tan explícito ni tan eficaz. Maritana fue una de las óperas más exitosas y divulgadas de su generación, y la suposición de Temperley de que pudo haber sido factor de condicionamiento musical para el genio deslumbrante de Bizet, no resulta nada improbable, ni audaz, ni aventurada. En el caso de Wallace, es el propio mosaico estilístico de su obra lo que le da un mérito particular y un interés fuera de lo común.

En este punto, la carrera composicional de Wallace se estanca definitivamente. Su siguiente ópera Matilda de Hungría (con libreto de Bunn), estrenada en el teatro Drury Lane el 22 de febrero de 1847, resulta un fracaso, tal vez porque sólo Meyerbeer podía componer en el estilo de la gran ópera de Meyerbeer. En 1848, la Ópera de París le comisionó una nueva obra, que sería Lurline, con libreto de Fitzball, la cual se anunció, también, entre las producciones del Covent Garden de ese año. Pero Lurline, otra vez en el espíritu y la intención de la gran ópera, no fue representada en ninguno de los dos teatros y hubo de esperar hasta el 23 de febrero de 1860 para su estreno, que fue realizado en el Covent Garden por la compañía de Louisa Pyne (1832-1904) y Harrison. Se rumoró 
que se había representado en Alemania en 1854, con el título de Loreley, pero nada se ha podido comprobar al respecto.

Wallace enfermó seriamente de la vista en el invierno de 1848 y al año siguiente se fue de nuevo a Sudamérica, con el objeto de "cambiar de aires y de ambiente", receta mágica de la medicina del siglo XIX, en la que Wallace obviamente había depositado su fe como cura de todo problema, emotivo, físico, financiero, social o profesional. En 1850, conoció en Nueva York a la pianista Hélène Stoepel (que debutó en la ciudad el 16 de junio del mismo año) y se casó con ella, sin preocuparse por la "formalidad" de que jamás se divorció de su primera esposa. En 1859, Wallace dirigió una carta a su cuñada Anna Kelly, en la cual le comenta su pensamiento de que el matrimonio con Isabella no había sido "legalizado" nunca, pero es difícil creer que tal criterio fuera compartido por ninguna autoridad judicial. A partir de enero de 1851, Hélène Stoepel apareció en todas sus actividades públicas y privadas, conciertos incluidos, como la "Señora Wallace", Tocó algunos conciertos con el compositor en Nueva York y permaneció siempre a su lado fiel, devota y enamorada. En 1854, Wallace publicó un álbum con diez canciones y algunas piezas para piano, impreso en Nueva York y "dedicado respetuosamente a las damas de los Estados Unidos".

La producción de Lurline fue un éxito, si bien jamás alcanzó las proporciones de Maritana. En Lurline, Wallace abunda en las escenas grandiosas, con coros, solistas y orquesta conjugados para producir el mayor impacto posible. La extraña combinación del esplendor al estilo de Meyerbeer (como el obtenido en el poderoso final del segundo acto) y una vena lírica e íntima derivada de Mendelssohn (como la evidente en When the night winds sweep the wave, Go from this heart y el tema en Fa sostenido menor de la obertura, obvios afluentes de las canciones sin palabras) resultó muy efectiva e interesante, sobre todo porque también amalgamó otros polos de contraste, como el casi verdiano Drain the cup of pleasure para coros de bebedores escénicos y la intensa pasión de su erótica Sweet form that on my dream gaze. George Bernard Shaw (18561950) dijo algo muy interesante luego de oír una reposición de Lurline: "Hay varios momentos en la ópera en que la corriente de gastado y trivial material de balada se eleva hasta una melodía que hierve con genuina emoción". Tal vez el problema toral fue que la gran ópera inglesa a la francesa de Wallace no rimaba con la idiosincrasia británica. Por ello, la popularidad de Lurline decayó rápidamente, Maritana duró tan sólo una generación y las otras tres óperas de Wallace no pudieron establecer una tradición inglesa de gran ópera nativa que pudiera favorecer al composi- 
tor. La bruja ámbar se estrenó el 28 de febrero de 1861 en Her Majesty's Theatre, El triunfo del amor fue representada por primera vez en el Covent Garden, el 3 de noviembre de 1862, y la función inaugural de La flor del desier to tuvo lugar el 12 de octubre de 1863, también en el Covent Garden. Ninguna de ellas tuvo algo más que un tibio y cortés aplauso.

Wallace, que había sufrido de "ataques al corazón" durante varios años, cuyas descripciones son más compatibles con la angina de pecho que con cualquier otra enfermedad, trabajaba con ahínco en su ópera Estrella en 1864, con la que esperaba rebasar sus tres últimas obras y alcanzar de nuevo el éxito de Maritana, cuando se puso sumamente enfermo. Suspendió la composición de Estrella y se fue a vivir a Passy, donde le visitaron muchas celebridades europeas, encabezadas por Rossini (1792-1868).

En septiembre de 1865 se mudó al castillo de Haget, donde su esposa norteamericana le cuidó esmerada y cariñosamente hasta que falleció, el 12 de octubre del mismo año. Sus restos fueron trasladados a Inglaterra e inhumados en el cementerio Kensal Green, el 23 de octubre de 1865. Hélène murió en Nueva York en 1885 e Isabella en Dublín en 1900.

La música de piano de Wallace, toda influida por Liszt (18111886) y Chopin y basada en el amplio mundo del material operático, es de gran dificultad virtuosistica y se ha olvidado por completo, Las obras para violín que se conservaron son muy escasas. Las canciones y obras vocales también se extinguieron, si bien The Bell Ringe alcanzó una buena popularidad que duró en Inglaterra hasta el principio del siglo XX. Las óperas, de indudable interés y ruda pero efectiva instrumentación, también están extintas, a pesar del sitio de Wallace como el único autor irlandés de ópera y uno de los muy escasos compositores líricos de la Gran Bretaña que alcanzaron un clamotoso éxito internacional. 